Özdemir, S. (2018). Türkçe Öğretmeni Adaylarının Konuşma Kaygısını Gidermede Hazırlıklı Konuşmaların Rolü. Abant İzet Baysal Üniversitesi Eğitim Fakültesi Dergisi, 18 (1), 361-374.

\title{
TÜRKÇE ÖĞRETMENİ ADAYLARININ KONUŞMA KAYGILARINI GIDERMEDE HAZIRLIKLI KONUŞMALARIN ROLÜ
}

\author{
Serpil ÖZDEMIR*
}

\section{ÖZET}

Türkçe öğretmenleri Türkçenin doğru ve etkili kullanımı ve iletişim açısından model olabilmelidir, çünkü Türkçe öğretmenleri sesini ve beden dilini etkili kullanabilen öğrenciler yetiştirmekle sorumludur. Genelde her öğretmenin özelde Türkçe öğretmenlerinin ve öğretmen adaylarının konuşma kaygıları kabul edilebilir düzeyde olmalıdır. Bu araştırmanın amacı Türkçe öğretmeni adaylarının konuşma kaygılarını gidermede hazırlıklı konuşmaların rolünü belirlemektir. Araştırmada deneysel desenlerden tek grup öntest-sontest deseni kullanılmıştır. Araştırmaya Bartın Üniversitesi Eğitim Fakültesi Türkçe Öğretmenliği Bölümünde okuyan 41 öğretmen adayı katılmıştır. Hazırlıklı konuşma çalışmaları Türkçe Öğretim Programı'nda önerilen etkinlikler çerçevesinde yapılmıştır. Böylece hem öğretmen adaylarının konuşma becerilerini geliştirmeleri hem de işbaşında yapacakları etkinlikleri içselleştirmeleri amaçlanmıştır. Araştırma verileri Öğretmen Adaylarına Yönelik Konuşma Kaygısı Ölçeği ile toplanmıştır. Araştırma sonunda öğretmen adaylarının konuşma kaygılarının öntestte orta düzeyde olduğu, sontestte düşük düzeyde olduğu; hazırlıklı konumalar yapmanın öğretmen adaylarının konuşma kaygılarını gidermede anlamlı bir fark yarattığı görülmüştür.

Anahtar Kelimeler: Türkçe öğretimi, konuşma kaygısı, hazırlıklı konuşma

\section{THE EFFECT OF PREPARED SPEAKING ON ELIMINATING THE SPEAKING ANXIETY OF PROSPECTIVE TURKISH TEACHER}

\begin{abstract}
Turkish teachers should be a model for correct and effective use of Turkish and communication because they are responsible for educating students who can effectively use their voice and body language. In general, the speaking anxiety of each teacher, especially Turkish teachers and teacher candidates, should be at an acceptable level. The purpose of this research is to determine the effect of prepared speaking on eliminating prospective Turkish teacher's speaking anxiety. The one group pretest-posttest design was used in the study. Forty-one teacher candidates from the Turkish Language Teaching Department of Bartin University participated in the research. Prepared speaking activities were made in the framework of the suggested activities in the Turkish Curriculum. Thus, it was aimed that both teacher candidates would improve their speaking skills and internalize the activities they would do at work. The research data were collected with the Speaking Anxiety Scale for Teacher Candidates. As a result of the research, it was seen that the teacher candidates' speaking anxiety were moderate at the pre-test and low at the post-test, and making prepared speaking made a meaningful difference on eliminating their speaking anxiety.
\end{abstract}

Key Words: Teaching Turkish, speaking anxiety, prepared speech

\footnotetext{
${ }^{*}$ Bartın Üniversitesi, Eğitim Fakültesi, Türkçe ve Sosyal Bilimler Eğitimi Bölümü / Türkçe Eğitimi Anabilim Dal,,serpilozdemir34@gmail.com
} 


\section{Serpil ÖZDEMIR}

\section{GİRIŞ}

Konuşma bireyin kendini ifade edebilmesini ve toplumsal süreçlere katılabilmesini sağlayan sözlü bir iletişim aracıdır. Bu iletişim aracını iyi kullananlar bireysel ilişkilerinde mutlu, sosyal ilişkilerinde başarılı olma bakımından avantajlıdır. Zihinde başlayan ve düşüncelerin sözle ifade edilmesiyle tamamlanan (Güneş, 2007) konuşma sürecinde etkili bir iletişim sağlamak asıl amaçtır. Etkili iletişim sağlamada konuşmacının konu hakkında birikimi ve dili iyi kullanmasının yanında, dil dışı unsurlarla sözlerinin örtüşmesi iyi bir konuşmacı algısı yaratmada önemlidir. Ancak konu hakkında uzman kişilerin bile toplum önünde bir konuşma yaparken konuşma dilini ve beden dilini iyi kullanamadığına şahit oluruz. Bunun nedenlerinden biri konuşma kaygısıdır. Toplum önünde konuşma birçok insan tarafindan yaşamdaki en büyük korkulardan biri olarak algılanmaktadır. Chapman Üniversitesinin 2016'da yaptığı araştırmada Amerikan toplumunun \%25.9'unun topluluk önünde konuşma korkusu yaşadığı belirlenmiştir ${ }^{1}$. Bireyin duygusal durumu; ses tonuna, hızına, jest ve mimiklerine yansımaktadır (Güneş, 2014). Bu nedenle konuşma kaygısı etkili bir iletişim sağlamada engel olabilmektedir.

"Kaygı, stres yaratan durumların bireyde oluşturduğu üzüntü, gerginlik gibi hoş olmayan duygusal ve gözlenebilen reaksiyonları" (Demirel, 2010, 78) ifade etmektedir. Kaygı düzeyi normal seviyelerde olduğunda kişiye, istek duyma, karar alma, alınan kararlar doğrultusunda enerji üretme ve bu enerjiyi kullanarak performansını yükseltme açısından yardımcı olur (Burkovik, 2009). İşimizi, sosyal yaşantımızı ve günlük sorumluluklarımızı olumsuz etkilemediği sürece kaygı duymak olağan kabul edilmektedir. Hatta düşük ve orta düzeydeki kaygı, performansı olumlu etkileyebilmektedir. Yüksek düzeyde kaygı; bilişsel, fiziksel ve davranışsal tepki bozukluklarına neden olmaktadır (Rector, Bourdeau, Kitchen ve Joseph-Massiah; 2008).

"Konuşma kaygısı, bir grup insan karşısında konuşma yapacak olan kişinin hissettiği tedirginlik ve başarısızlık duygusu olarak açıklanabilir" (Katrancı ve Kuşdemir, 2015, 418). Düşük ve orta düzeyde konuşma kaygısı "yaratıc1, coşkulu ve olumlu davranmaya teşvik eden güçlü bir motivasyon işlevi” (Maviş, 2013, 64) görebilmektedir. Yüksek düzeyde konuşma kaygısı konuşmayı ve konuşmacıyı olumsuz etkilemektedir. Yüksek kaygı yaşayan konuşmacıda düşünce akışının kesintiye uğraması, olumlu duyguların bir anda kaybolması, ellerin ve vücudun titremesi, kalbin çarpması, sesin titremesi, başkalarıyla göz göze gelememe durumları oluşmaktadır (Vural, 2004). Konuşma kaygısı çalışmalarının (Akkaya, 2012; Arslan, 2012; Suroğlu Sofu, 2012) sonuçları; bilişsel, fiziksel ve davranışsal bakımdan sınıflandırıldığında karşılaşılan olumsuzluklar daha net görülebilmektedir. Bilişsel olarak söyleyeceklerini unutma, söylediklerini doğru ve etkili bir biçimde ifade edip edememe hususunda kendini konuşma anında sorgulama, konuşmaya odaklanamama; fiziksel olarak aşırı terleme, sesin titremesi, ellerin titremesi, ağzın kuruması, yüzün kızarması; davranışsal olarak dinleyici ile göz göze gelememe, rahatsız olduğunu gösteren abartılı hareketler yapma, güvenli bir duruş sergileyememe, konuşmayı kısa kesme, aşırı hızlı konuşma, konuşma boşlukları yapma gibi sorunlar görülmektedir. $\mathrm{Bu}$ sorunları yaşayan kişilerin; duygu, düşünce ve bilgilerini etkili biçimde aktarabileceği söylenemez. Bu nedenlerle konuşma kaygısının kabul edilebilir düzeyi düşük veya orta düzeydir.

\footnotetext{
${ }^{1}$ https://blogs.chapman.edu/wilkinson/2016/10/11/americas-top-fears-2016/
} 
Türkçe öğretmeni adaylarının konuşma kaygılarını gidermede hazırlıklı...

Öğretmenlik konuşmaya dayalı mesleklerden biridir. Her öğretmenin doğru ve etkili konuşması, öğrencilerine örnek olması bakımından, beklenen bir durumdur. Özellikle Türkçe öğretmenleri Türkçenin doğru ve etkili kullanımı ve iletişim açısından model olabilmelidir (MEB, 2008). Çünkü Türkçe öğretmenleri sesini ve beden dilini etkili kullanabilen (MEB, 2006) öğrenciler yetiştirmekle sorumludur. Genelde her öğretmenin, özelde Türkçe öğretmenlerinin ve öğretmen adaylarının konuşma kaygıları, konuşma performansının istenen şekilde gerçekleşmesi için düşük veya orta düzeyde olmalıdır.

Konuşma, sağlıklı olan her insanda bulunan bir yetidir, ancak her insanın doğru ve etkili konuşabildiği söylenemez. Doğru ve etkili konuşabilmek bir beceridir. "Beceriler, hiçbir uğraş vermeden ve kendiliğinden gelişmez. İnsanın sahip olduğu hangi beceri olursa olsun o becerinin geliştirilmesi için eğitim çalışmaları, uygulamaları yapmak şarttır" (Doğan, 2009, 191). Türkçe öğretmeni adaylarının hem kişisel konuşma becerilerini geliştirmeleri hem de öğrencilerine konuşma eğitimi verebilmeleri için Türkçe öğretmenliği lisans programında Anlatma Teknikleri I: Konuşma Eğitimi dersi yer almaktadır. Bu ders, konuyla ilgili teorik bilgilerin yanında hazırlıklı ve hazırlıksız konuşma uygulamalarına dayanmaktadır. Hazırlıklı konuşmalar konuyla ilgili içeriğin planlanması, bilgi ve belgelerin toplanması, gerekirse bilgi teknolojilerinden yararlanarak konunun sunulması aşamalarılla ve genellikle resmi ortamlarda gerçekleşmektedir. Hazırlıksız konuşmalar ise doğrudan o anki bilgi birikimimize dayalı olarak günlük hayatın içinde, ikili ilişkilerimizde yaptığımız konuşmalardır (Yalçın, 2012).

Konuşma kaygısı genellikle topluluk karşısında yapılan hazırlıklı konuşmalarda görülmektedir. Bu durumun nedenleri arasında "bilgi eksikliği, dinleyicilerden olumsuz tepki alma endişesi, utangaç bir mizaca sahip olma, diksiyon problemleri, özgüven eksikliği” (Arslan, 2012, 226) sayılabilir. Kaygıyı aşabilmek ve güvenli bir konuşmacı olabilmek için bilgiyle donanmak, kaygı nedenlerinin farkında olmak, iyi bir ön hazırlık yapmak ve pek çok alıştırma yapmak gereklidir. Araştırmalar Türkçe öğretmeni adaylarının konuşma uygulamaları yaptıktan sonra konuşma kaygılarının azaldığını göstermektedir (Bulut, 2015; Katrancı ve Kuşdemir, 2015; Sevim, 2014).

Alanyazında öğretmen adaylarının konuşma becerilerine yönelik olarak yapılan çalışmalar çok yakın geçmişte ortaya çıkmaya başlamıştır. Öğretmen adaylarının konuşma becerisine yönelik çalışmaların halen sınırlı sayıda olduğu dikkati çekmektedir. Genel tarama yöntemiyle Türkçe öğretmeni adaylarının ve farklı branşlardaki öğretmen adaylarının konuşma kaygılarını (Baki ve Karakuş, 2015; Lüle Mert, 2015; Özkan ve Kınay, 2015; Temiz, 2015); güzel konuşmaya (Başaran ve Erdem, 2009) ve topluluk karşısında konuşmaya ilişkin görüşlerini (Arslan, 2012), konuşma eğitimi dersine yönelik tutumlarını (Ceran, 2012) belirlemeye yönelik çalışmalar yapılmıştır. Nitel yönteme dayalı olarak öğretmen adaylarının konuşma sorunlarını (Akkaya, 2012) ve öğretmen adaylarının gözünden Türkçe öğretmenlerinin konuşma becerilerini (Er ve Demir, 2013) belirlemeye yönelik çalışmalar görülmektedir. Konuşma becerisi araştırmalarına hız kazandırabilecek ölçek geliştirme çalışmaları da oldukça yenidir. Bu çalışmalarda öğretmen adaylarının konuşma öz yeterliklerini (Aydın, 2013; Katrancı ve Melanlığlu, 2013), konuşma kaygılarını (Kinay ve Özkan, 2014; Sevim, 2012; Suroğlu Sofu, 2012) ve etkili konuşma becerilerini (Çintaş Yıldız ve Yavuz, 2012) ölçmeye yönelik ölçekler geliştirilmiştir. Deneysel yöntemle mikro öğretim tekniğinin (Bulut, 2015) ve drama uygulamalarının (Sevim, 2014) Türkçe öğretmeni adaylarının konuşma kaygılarına 


\section{Serpil ÖZDEMIR}

etkisi; Türkçe öğretmenliği dışında, farklı branşlardaki öğretmen adaylarının Sözlü Anlatım dersi uygulamalarından önce ve sonra konuşma kaygıları (Katrancı ve Kuşdemir, 2015) belirlenmiş̧ir.

Araştırmalardan çıkan genel sonuçlar; öğretmen adaylarının Türkçeyi konuşmada kendilerini yeterli bulmadıklarını, uygulamaya dayalı çalışmalara ihtiyaç duyduklarını, topluluk karşısında konuşurken kaygılı olduklarını, uygulamalı çalışmalarla kendilerini geliştirebildiklerini, sınıf düzeyi arttıkça kaygının azaldı̆̆ını göstermektedir.

\subsection{Araştırmanın Amacı}

$\mathrm{Bu}$ araştırmanın amacı Türkçe öğretmeni adaylarının konuşma kaygılarını gidermede hazırlıklı konuşmaların rolünü belirlemektir. Araştırmanın problem cümlesi "Öğretmen adaylarının konuşma kaygısını gidermede hazırlıklı konuşma yapmanın etkisi nedir?" şeklinde belirlenmiştir. Araştırma şu alt problemler çerçevesinde ele alınmıştır:

1- Türkçe öğretmeni adaylarının hazırlıklı konuşmalar öncesinde ve sonrasında konuşma kaygıları ne düzeydedir?

2- Türkçe öğretmeni adaylarının konuşma kaygısı puanları hazırlıklı konuşmalar öncesinde ve sonrasında anlamlı bir fark göstermekte midir?

\subsection{Araştırmanın Önemi}

Öğretmen adayları konuşma uygulamaları yaptıkça geliştirmeleri gereken yönlerini görebilecek, becerilerini daha etkili kullanabilmek için güven kazanacaklardır. Türkçe öğretmeni adaylarına verilen konuşma eğitimi dersinin konuşma ile ilgili bilgi, beceri ve güven kazandırması ve sonuçta konuşma kaygısını azaltması beklenir. Öğretmen adaylarının mesleğe başladıklarında konuşma yoluyla pek çok bilgi aktaracakları ve öğrencilerine örnek olacakları düşünüldüğünde konuşma becerisi mesleki başarının çok önemli bir unsuru durumundadır. "Konuşma eğitimi, çevreye uyma yeteneğimizi ve toplumsal yararlılığımızı artıran yeni rollerimizde üstün başarı kazanmamıza yardım eder." (Taşer, 1992, 63). Bu araştırma öğretmen adaylarının konuşma becerilerini geliştirmelerini sağlayabilmek ve gözlemleyebilmek açısından önemlidir. Ayrıca hazırlıklı konuşma çalışmaları rastgele bir konuda değil, Türkçe Öğretim Programı'nda önerilen etkinlikler çerçevesinde yapılmıştır. Bu yönüyle öğretmen adaylarının işbaşında uygulamaları beklenen etkinlikleri içselleştirebilmelerini sağlaması açısından önemlidir. Yapılan literatür taramasında Türkçe öğretmeni adaylarının konuşma kaygılarını Konuşma Eğitimi dersine dayalı olarak deneysel yöntemle ele alan bir araştırmaya rastlanmamıştır. Araştırma bu yönüyle özgündür ve literatüre katkı sağlayacağı öngörülmektedir. 
Türkçe öğretmeni adaylarının konuşma kaygılarını gidermede hazırlıklı...

\section{YÖNTEM}

\subsection{Araştırma Modeli}

Araştırma tek grup öntest-sontest modeli ile yapılmıştır. Bu modelde bir grup üzerinde bağımsız değişkenin etkisi test edilir. Burada esas olan, deney öncesi ile deney sonrası arasında bağımsız değişkenin denekler üzerindeki etkisinin ne olduğudur (Köse, 2013). $\mathrm{Bu}$ araştırmada hazırlıklı konuşmalar bağımsız değişken durumundadır.

\section{2. Çalışma Grubu}

Araştırma, 2015-2016 eğitim öğretim yılında, Bartın Üniversitesi Eğitim Fakültesi, Türkçe Öğretmenliği bölümünde okuyan üçüncü sınıf öğrencileri ile yürütülmüştür. Araştırmaya Anlatma Teknikleri I: Konuşma Eğitimi dersini alan 41 öğrenci katılmıştır.

\subsection{Veri Toplama Aracı}

Araştırmanın verileri Sevim (2012) tarafından geliştirilen "Öğretmen Adaylarına Yönelik Konuşma Kaygısı Ölçeği” ile toplanmıştır. Ölçek sahibinden, ölçeğin bu araştırmada kullanılmasına yönelik izin alınmıştır. 20 madde ve üç alt boyuttan oluşan ölçek 5'li Likert tipindedir. Ölçek "konuşmacı odaklı kaygı”, "çevre odaklı kaygı" ve "konuşma psikolojisi”" alt boyutlarından oluşmaktadır. Ölçeğin güvenirlik katsayısı .91 olarak belirlenmiştir. Bu araştırmada ölçeğin bütünü dikkate alınmıştır ve Cronbach Alfa güvenirlik katsayısı .92 olarak belirlenmiştir. Ölçeğin puanlamasında; "1-Hiçbir zaman, 2-Çok az, 3-Bazen, 4-Çoğu Zaman, 5-Her Zaman" kaygılı olmayı ifade etmektedir. Ölçek maddelerinin her biri için 1-2.3 arası düşük düzeyde kaygıyı, 2.4-3.7 arası orta düzeyde kaygıyı, 3.8-5 arası yüksek düzeyde kaygıyı ifade etmektedir. Ölçek toplamından ise alınabilecek en düşük puan 20, en yüksek puan 100'dür. Ölçek genelinde 20-46.6 puan arası düşük, 46.7-73.3 arası orta ve 73.4-100 arası yüksek düzeyde kaygıyı göstermektedir.

\subsection{Veri Toplama Süreci}

Araştırmanın verileri 2015-2016 bahar yarıyılında, Anlatma Teknikleri I: Konuşma Eğitimi dersinde yapılan sözlü sunumlar sürecinin öncesinde ve sonrasında toplanmıştır. Konuşma Eğitimi dersi haftada 2 saat teori ve 2 saat uygulamaya dayalı olarak yürütülen bir derstir. Sunumlar dersin uygulamaya dayalı olan 2 saatlik kısmında yapılmış, hazırlıksız konuşma uygulamaları tamamlandıktan sonra hazırlıklı konuşma uygulamalarına geçilmiştir. Araştırma verileri hazırlıklı konuşmalara dayalıdır. Hazırlıklı konuşmalar 8 haftada tamamlanmıştır. Sözlü sunumlar MEB 2006 Türkçe Dersi Öğretim Programı'nda yer alan etkinlikler çerçevesinde yapılmıştır. Öğretmen adayları bu etkinliklerden birini seçerek sunumlarını yapmışlardır. Çalışma sürecinde "Bizimkiler, Canlandırma (Hacivat ve Karagöz), Ah Bir Bakan Olsam, Meddah Sınıfta, Maymun Gözünü Açtı, Ben Bir Rehberim, Çapraz Sorgu, Hayallerim ve Ben, Diyalog Kurma, Güzel Bir Gün" etkinlikleri öğretmen adayları tarafından konuşma konuları olarak seçilmiş ve sunulmuştur. Bizimkiler, Canlandırma (Hacivat ve Karagöz), Çapraz Sorgu ve Diyalog Kurma etkinlikleri iki veya daha fazla öğrenci tarafından gerçekleştirilmiştir. Diğer etkinlikler bireysel olarak yapılmıştır. Konuşma süresi kişi başı 10 dakika olarak 


\section{Serpil ÖZDEMIR}

planlanmıştır. Konuşmalarda mümkün olduğunca resim, canlandırma ve benzetime yer verilmesi istenmiştir.

Etkinliklerin içeriğinde şunlar yer almıştır:

Bizimkiler: Aile bireylerinin pazarlık yapma, televizyon seyretme gibi bazı durumlarda verdikleri tepkileri dramatize etme.

Canlandırma: Hacivat ve Karagöz gölge oyunu.

Ah Bir Bakan Olsam: Milli Eğitim Bakanı ve Gençlik ve Spor Bakanı rolleri.

Meddah Sınıfta: Hikâye canlandırma.

Maymun Gözünü Açtı: Deyimlerin hikâyeleri ve kişisel yaşamda bu deyime ilişkin gözlemler.

Ben Bir Rehberim: Bir yerin tarihi, doğal ve kültürel özellikleri ile tanıtımı.

Çapraz Sorgu: Hayvan hakları konusunda iki kişinin soru sorması bir kişinin cevaplamasi.

Hayallerim ve Ben: Öğretmen olma, başarılı bir sporcu olma, tanınmış bir yazar olma gibi hayallerin rol modellerini tanıtma ve hayalleri gerçekleştirme çabaları.

Diyalog Kurma: Ailesi karşı çıktığı halde güzel sanatlarda okumak isteyen bir gencin ailesini ikna etme, eve hayvan almak için aileyi ikna etme.

Güzel Bir Gün: Yanlış anlamadan dolayı arkadaşını kırma, sınavda başarısız olma nedenleriyle yaşanan kötü bir günü güzel bir güne çevirmek için yapılanlar.

Konuşmalar akranlar ve öğretim elemanı tarafından dil ve anlatım, içerik ve sunum bakımından değerlendirilmiş ve konuşmacılara dönütler verilmiştir. Değerlendirme aracı olarak Temizkan (2009) tarafindan geliştirilen "Konuşma Becerisine Yönelik Akran Değerlendirme Formu" kullanılmıştır.

\subsection{Verilerin Çözümlenmesi}

Araştırma verilerinin normal dağılım gösterip göstermediğini belirlemek için çarpıklık katsayıları incelenmiştir. Çarpıklık katsayılarının -.373 ile +.918 aralığında olduğu görülmüştür. "Çarpıklık katsayıları +/-1 sınırları içinde kalıyorsa, puanların normalden aşırı bir sapma göstermediği şeklinde yorumlanabilir” (Büyüköztürk, 2011, 40). Ayrıca Q-Q grafikleri incelenmiş ve noktaların 45 derecelik doğru üzerinde veya yakın bir durumda olduğu görülmüștür. "Q-Q grafiğginde noktalar 45 derecelik doğru üzerinde veya yakın bir durumda gözüküyorsa normal dağılıma uygunluktan söz edilebilir" (Büyüköztürk, 2011, 40). Verilerin normal dağılım gösterdiği belirlendiği için parametrik testler ile veriler analiz edilmiștir. Türkçe öğretmeni adaylarının hazırlıklı konuşmalar öncesinde ve sonrasında konuşma kaygılarının ne düzeyde olduğunu belirmek için betimsel istatistik analizi yapılmış, ortalama ve standart sapma değerlerine bakılmıştır. Konuşma kaygısı puanlarının hazırlıklı konuşmalar öncesinde ve sonrasında anlamlı bir fark gösterip göstermediğini belirlemek için tek örneklem $t$ testi yapılmıştır. Veriler SPSS 15.0 bilgisayar programı ile analiz edilmiştir. 
Türkçe öğretmeni adaylarının konuşma kaygılarını gidermede hazırlıklı...

\section{BULGULAR}

Türkçe öğretmeni adaylarının hazırlıklı konuşmalar öncesinde ve sonrasında konuşma kaygılarının ne düzeyde olduğunu belirlemek üzere betimsel analiz yapılmıştır. Yapılan öntest ve sontest sonuçları Tablo 1'de görülmektedir.

\section{Tablo 1.}

Türkçe Öğretmeni Adaylarının Sunum Öncesi ve Sonrası Konuşma Kaygı Düzeyleri

\begin{tabular}{|c|c|c|c|c|c|}
\hline \multirow[b]{2}{*}{ Ölçek Maddeleri } & \multicolumn{3}{|c|}{ Ortalama } & \multicolumn{2}{|c|}{ SS } \\
\hline & $\mathbf{N}$ & Öntest & Sontest & Öntest & Sontest \\
\hline 1.Konuşurken beden dilini kullanmaktan çekinirim. & 41 & 2,49 & 1,98 & ,93 & ,94 \\
\hline $\begin{array}{l}\text { 2.Konuşurken muhatabımın gözlerine bakmaktan } \\
\text { çekinirim. }\end{array}$ & 41 & 2,24 & 1,95 & ,94 & ,84 \\
\hline $\begin{array}{l}\text { 3.Önümde bir metin olmadan konuşmak bende } \\
\text { kaygı uyandırır. }\end{array}$ & 41 & 2,95 & 2,61 & ,87 & ,89 \\
\hline $\begin{array}{l}\text { 4.Sempozyum, panel, konferans vb. etkinliklerde } \\
\text { konuşma düşüncesi beni gerer. }\end{array}$ & 41 & 3,34 & 2,98 & ,93 & 1,06 \\
\hline $\begin{array}{l}\text { 5.Konuşma konuma farklı açılardan } \\
\text { yaklaşamadığım düşüncesi beni endişelendirir. }\end{array}$ & 41 & 2,98 & 2,51 & ,91 & ,98 \\
\hline $\begin{array}{l}\text { 6.Konuşurken canlı ve coşkulu davranmayı } \\
\text { beceremem. }\end{array}$ & 41 & 2,66 & 2,05 & 1,02 & ,92 \\
\hline $\begin{array}{l}\text { 7.Kendimi dinleyicilerin gözünden görme ve } \\
\text { eleştirme düşüncesi beni rahatsız eder. }\end{array}$ & 41 & 2,39 & 1,68 & ,89 & ,79 \\
\hline $\begin{array}{l}\text { 8.Konuşma hızımı iyi ayarlayamadığım zaman } \\
\text { elim ayağıma dolaşır. }\end{array}$ & 41 & 2,61 & 2,34 & ,86 & ,83 \\
\hline 9.Topluluk önünde konuşmaktan korkarım. & 41 & 2,71 & 2,22 & ,98 & ,91 \\
\hline $\begin{array}{l}\text { 10.Konuşurken zihnimdekileri tam olarak } \\
\text { karşılayacak sözcükleri ve cümleleri kullanmada } \\
\text { sıkıntı yaşarım. }\end{array}$ & 41 & 2,73 & 2,46 & ,84 & ,78 \\
\hline $\begin{array}{l}\text { 11.Herhangi bir tartışma ortamında söz alarak } \\
\text { konuşmaya katılmaktan çekinirim. }\end{array}$ & 41 & 2,37 & 2,00 & ,92 & 1,00 \\
\hline $\begin{array}{l}\text { 12. Tanımadığım insanların karşısında } \\
\text { konuşmaktan utanırım. }\end{array}$ & 41 & 2,46 & 2,10 & ,93 & ,97 \\
\hline $\begin{array}{l}\text { 13.Bir konu hakkında aniden konuşmam } \\
\text { istendiğinde kaygılanırım. }\end{array}$ & 41 & 2,88 & 2,41 & ,93 & ,89 \\
\hline $\begin{array}{l}\text { 14. Karşı cinsten biriyle konuşurken } \\
\text { heyecanlanırım. }\end{array}$ & 41 & 2,10 & 1,71 & ,889 & 87 \\
\hline $\begin{array}{l}\text { 15.Öğretmen ya da amirimle konuşmam } \\
\text { gerektiğinde kendimi kaygilı hissederim. }\end{array}$ & 41 & 2,24 & 1,78 & ,94 & ,76 \\
\hline $\begin{array}{l}\text { 16.İyi tanımadığım biriyle telefonda konuşurken } \\
\text { kendimi gergin hissederim. }\end{array}$ & 41 & 2,12 & 1,73 & 1,00 & ,84 \\
\hline $\begin{array}{l}\text { 17. Otorite pozisyonunda olan birisiyle konuşurken } \\
\text { kendimi kaygll hissederim. }\end{array}$ & 41 & 2,56 & 2,20 & 1,00 & ,90 \\
\hline $\begin{array}{l}\text { 18.Konuşurken bana ayrılan sürenin } \\
\text { yetmeyeceğinden korkarım. }\end{array}$ & 41 & 2,41 & 2,17 & ,921 & ,919 \\
\hline $\begin{array}{l}\text { 19.Insanlara kendimle ilgili konulardan } \\
\text { bahsederken utanırım. }\end{array}$ & 41 & 2,12 & 1,78 & ,954 & ,881 \\
\hline $\begin{array}{l}\text { 20.Konuşurken sözümün kesilmesi bende endişe } \\
\text { uyandırır. }\end{array}$ & 41 & 2,66 & 2,20 & ,938 &, 715 \\
\hline
\end{tabular}




\section{Serpil ÖZDEMIR}

Araştırma grubunun konuşma kaygısı öntest puanları 2.10 ile 3.34 arasında değişmektedir. Bütün maddelerin ortalaması 2.55 olarak hesaplanmıştır. Bu puanlar öğretmen adaylarının konuşma kaygılarının orta düzeyde olduğunu göstermektedir. En düşük ortalamaya sahip maddeler "Karşı cinsten biriyle konuşurken heyecanlanırım $(\bar{X}=2.10)$ ", "İyi tanımadı̆̆ım biriyle telefonda konuşurken kendimi gergin hissederim ( $\bar{X}=2.12)$ " ve "Insanlara kendimle ilgili konulardan bahsederken utanırım $(\bar{X}=2.12)$ " maddeleridir. Bu maddeler günlük hayatın içinde bireysel ilişki durumlarını ifade etmektedir. En yüksek kaygı duyulan madde ise "Sempozyum, panel, konferans vb. etkinliklerde konuşma düşüncesi beni gerer $(\bar{X}=3.34)$ " maddesidir.

Sontest puanlarına bakıldığında bütün maddelerin ortalamalarında hafif düşüş olduğu görülmektedir. Son test puanları 1.68 ile 2.98 arasındadır. Bütün maddelerin ortalaması 2.14 olarak hesaplanmıştır. Ölçek maddelerinin her biri için 1-2.3 arası düşük düzeyde kaygıyı, 2.4-3.7 arası orta düzeyde kaygıyı, 3.8-5 arası yüksek düzeyde kaygıyı gösterdiğinden son test puanları düşük düzeydedir.

Sontest puanlarındaki farkın anlamlı olup olmadığını belirlemeye yönelik ikinci alt problem için eşleştirilmiş gruplar $\mathrm{t}$ testi yapılmıştır. Test sonuçları Tablo 2'de görülmektedir.

\section{Tablo 2.}

Türkçe Öğretmeni Adaylarının Konuşma Kaygısı Puanlarının Hazırlıklı Konuşmalar Sonrasinda Farkı

\begin{tabular}{lcccccc}
\hline & $\mathbf{N}$ & $\overline{\boldsymbol{X}}$ & $\mathbf{S}$ & $\mathbf{s d}$ & $\mathbf{t}$ & $\mathbf{p}$ \\
\hline Öntest & 41 & 51,0244 & 10,68524 & \multirow{2}{*}{40} & \multirow{2}{*}{9.10} & \multirow{2}{*}{.000} \\
Sontest & 41 & 42,8537 & 11,11207 & & & \\
\hline
\end{tabular}

$\mathrm{p}<.01$

Öğretmen adaylarının hazırlıklı konuşmalar sonrasında konuşma kaygılarında anlamlı bir azalma olduğu görülmektedir $\mathrm{t}(40)=9.10, \mathrm{p}<.01$. Ölçek genelinde $20-46,6$ puan arası düşük, 46,7-73,3 arası orta düzeyde kaygıyı göstermektedir. Uygulama öncesinde konuşma kaygı puanları ortalaması $\bar{X}=51$ orta düzeye karşılık gelmektedir. Hazırlıklı konuşma uygulamalarından sonra konuşma kaygısı $\bar{X}=42,9$ 'a düşmüştür. $\mathrm{Bu}$ puan düşük düzeyde kaygıyı göstermektedir. Sonuç olarak hazırlıklı konuşma uygulamalarının öğretmen adaylarının konuşma kaygılarını azaltmada önemli bir etkiye sahip olduğu söylenebilir.

\section{TARTIŞMA, SONUÇ VE ÖNERİLER}

$\mathrm{Bu}$ araştırma Türkçe öğretmeni adaylarının konuşma kaygılarını gidermede hazırlıklı konuşmaların bir etkisi olup olmadığını belirlemek üzere yapılmıştır. Araştırma tek grup öntest-sontest modeli ile yürütülmüştür.

Yapılan öntestte öğretmen adaylarının konuşma kaygılarının bütün maddelerde orta düzeyde olduğu görülmüştür. Yüksek düzeyde kaygı duyulan maddeler görülmemiştir. En düşük kaygı puanlarının bireysel iletişime yönelik maddelerde olduğu belirlenmiştir. En yüksek kayg düzeyi $(\bar{X}=3.34)$ "Sempozyum, panel, konferans vb. etkinliklerde konuşma düşüncesi beni gerer.” maddesinde görülmüştür. Bu sonuçlar topluluk önünde konuşma yapmanın hazırlıksız konuşmalardan daha yüksek kaygı yarattığını göstermektedir. Akkaya (2012) da araştırmasında topluluk karşısında heyecanlanmanın, öğretmen adayları tarafindan en çok ifade edilen konuşma sorunu olduğunu tespit etmiştir. Arslan (2012), üniversite öğrencilerinin "alaycı davranışlarla karşılaşma, özgüven eksikliği, yanlış veya eksik bilgi verme korkusu, 
Türkçe öğretmeni adaylarının konuşma kaygılarını gidermede hazırlıklı...

utangaç mizaç, topluluk karşısında konuşmaya alışkın olmama, Türkçeye hâkim olmama, anlaşılmama endişesi” gibi nedenlerle topluluk karşısında konuşma yapmaktan kaçındıklarını belirlemiştir.

Sontest puanlarının bütün maddelerde biraz düştüğü, bütün maddelerin ortalamasının 2.14 olduğu görülmüştür. Son test ortalaması konuşma kaygısının düşük düzeyde olduğunu göstermektedir. Bu sonuç Özkan ve Kinay (2015)'ın ve Temiz (2015)'in farklı branşlardan öğretmen adaylarıyla ve Baki ve Karakuş (2015)'un Türkçe öğretmenleriyle yaptıkları araştırmalarla örtüşmektedir. Lüle Mert (2015) ise Türkçe öğretmeni adaylarının konuşma kaygı düzeylerinin zayıf olduğunu belirlemiştir. Düşük ve orta düzeydeki kaygı daha iyi performans sergilemeyi desteklediği için (Burkovik, 2009) öğretmen adaylarının kaygı düzeyleri normal kabul edilebilir.

Ölçek genelinde ortalamalar arasındaki farkın anlamlı olup olmadığına bakıldığında, \% 99 güven aralığında farkın anlamlı olduğu belirlenmiştir. Uygulamalara dayalı deneysel çalışmalarda benzer sonuçlar görülmektedir (Bulut, 2015; Hancock, Stone, Brundage ve Zeigler, 2010; Katranc1 ve Kuşdemir, 2015; Sevim, 2014). Sonuç olarak, konuşma eğitimine dayalı bilgilerden sonra yapılan hazırlıklı konuşma uygulamalarının öğretmen adaylarının konuşma kaygılarını azaltmada önemli bir etkiye sahip olduğu söylenebilir.

$\mathrm{Bu}$ araştırmanın iki yönden sınırlılıkları bulunmaktadır. Birincisi araştırmanın, konuşma kaygısını gidermede hazırlıklı konuşmaların rolüyle sınırlı olmasıdır. İkincisi Anlatma Teknikleri I: Konuşma Eğitimi dersi Türkçe Öğretmenliği bölümlerinde 3. sınıfta okutulmaktadır ve yarısı teoriye yarısı uygulamaya dayanmaktadır. Uygulama yapmayacak bir fakülte düşünülemeyeceği için aynı eğitim geçmişine sahip bir kontrol grubu belirlenmemiştir. Konuşma deneyimlerinin konuşma kaygısını azaltan önemli bir faktör olduğu bilinmektedir. Bununla birlikte dinleyicinin özellikleri, öğreticinin tutumları, konuşmanın konusu konuşma kaygısını azaltan veya artıran faktörler arasında sayılmaktadır (Neer ve Kircher, 1989). Çoklu gruplarla yapılacak deneysel çalışmalarla bu faktörlerin konuşma kaygısını azaltmada rollerinin belirlenmesi gereklidir.

Bu araştırmanın uygulamaları MEB 2006 Türkçe Öğretim Programı'ndaki etkinliklerden öğrencilerin istediği birini seçmesine dayalı olarak yapılmıştır. Çalışma sürecinde başkasının rolüne girmeye dayalı olarak "Bizimkiler, Canlandırma (Hacivat ve Karagöz), Ah Bir Bakan Olsam, Meddah Sinıfta, Ben Bir Rehberim, Çapraz Sorgu, Diyalog Kurma"; bireyin kendi yaşantısına dayalı olarak "Maymun Gözünü Açtı, Hayallerim ve Ben, Güzel Bir Gün" etkinlikleri sunulmuştur. Rol yapma ve bireysel içerikli konuşma etkinliklerinin hangisinin konuşma kaygısını gidermede daha etkili olduğunu belirlemeye yönelik deneysel çalışmalar yapilabilir.

$\mathrm{Bu}$ araştırma, hazırlıklı konuşmaların öğretmen adaylarının konuşma kaygısını nasıl etkilediğine odaklanmıştır. Öğretmen adaylarının konuşma kaygılarının kaynakları ve konuşma kaygısıyla baş etme stratejilerinin neler olduğu belirlenmemiştir. Konuyu bu açılardan ele alacak çalışmalara ihtiyaç vardır.

"Kaygıyı yok edemeyiz, ancak bize karşı değil, bizim için çalışmasına yardımcı olabiliriz.” (Yau-hau Tse, 2011, 9). Bunun için konuşma eğitimi derslerinde sözlü anlatım uygulamalarının ihmal edilmemesi, öğretmen adaylarının sempozyum, panel, konferans gibi konuşma ortamlarında deneyim sahibi olmaları için desteklenmeleri ve kaygı ile baş etme stratejileri hakkında bilgilendirilmeleri önerilmektedir. 


\section{KAYNAKÇA}

Akkaya, A. (2012). Öğretmen adaylarının konuşma sorunlarına ilişskin görüşleri. Mustafa Kemal Üniversitesi Sosyal Bilimler Enstitüsü Dergisi, 9 (20), 405-420.

Arslan, A. (2012). Üniversite öğrencilerinin "topluluk karşısında konuşma" ile ilgili çeşitli görüşleri (Ağrı İbrahim Çeçen Üniversitesi örneği). Turkish Studies International Periodical For The Languages, Literature and History of Turkish or Turkic , 7 (3), 221-231.

Baki, Y. ve Karakuş, N. (2015). A research on speech anxiety of prospective Turkish teachers. Anthropologist, 21(1,2), 271-276.

Başaran, M. ve Erdem, İ. (2009). Öğretmen adaylarının güzel konuşma becerisi ile ilgili görüşleri üzerine bir araştırma. Kastamonu Eğitim Dergisi, 17 (3), 743-754.

Bulut, K. (2015). Mikro öğretim tekniğinin Türkçe öğretmen adaylarının konuşma beceri ve kaygılarına etkisi. (Yayımlanmamış Doktora Tezi). Gazi Üniversitesi Eğitim Bilimleri Enstitüsü, Ankara.

Burkovik, Y. (2009). Kaygllanacak ne var. İstanbul: Timaş Yayınları.

Büyüköztürk, Ş. (2011). Sosyal bilimler için veri analizi el kitabı. Ankara: Pegem Akademi.

Ceran, D. (2012). Türkçe öğretmeni adaylarının konuşma eğitimi dersine yönelik tutumlarının değerlendirilmesi. The Journal of Academic Social Science Studies, 5 (8), 337-358.

Çintaş Yıldız, D. ve Yavuz, M. (2012). Etkili konuşma ölçeği: bir ölçek geliştirme çalışması. Turkish Studies - International Periodical For The Languages, Literature and History of Turkish or Turkic, 7 (2), 319-334.

Demirel, Ö. (2010). Eğitim sözlüğ̈̈. Ankara: Pegem Akademi Yayınları.

Er, O. ve Demir, Ö. (2013). Konuşma becerisinin Türkçe öğretmenleri tarafından kullanılabilirliğine ilişkin Türkçe öğretmeni adaylarının görüşlerinin incelenmesi. Turkish Studies - International Periodical For The Languages, Literature and History of Turkish or Turkic, 8 (1), 1417-1436.

Güneş, F. (2007). Türkçe öğretimi ve zihinsel yapılandırma. Ankara: Nobel Yayın Dağıtım.

Güneş, F. (2014). Türkçe öğretimi yeni yaklaşımlar. Ankara: Pegem Akademi.

Hancock, A. B., Stone, M. D., Brundage, S. B. ve Zeigler, M. T. (2010). Public speaking attitudes: does curriculum make a difference? Journal of Voice. 24 (3), 302307.

Katrancı, M. ve Kuşdemir, Y. (2015). Öğretmen adaylarının konuşma kaygılarının incelenmesi: sözlü anlatım dersine yönelik bir uygulama. Dicle Üniversitesi Ziya Gökalp Eğitim Fakültesi Dergisi, 24 (2015), 415-445.

Katranc1, M. ve Melanlıoğlu, D. (2013). Öğretmen adaylarına yönelik konuşma öz yeterlik ölçeği: geçerlik ve güvenilirlik çalışması. The Journal of Academic Social Science Studies, 6 (6), 651-665. 
Türkçe öğretmeni adaylarının konuşma kaygılarını gidermede hazırlıklı...

Kinay İ. ve Özkan, E. (2014). Öğretmen adayları için konuşma kaygısı ölçeği (ÖAKKÖ) geliştirilmesi: geçerlik ve güvenirlik çalı̧̧ması. Turkish Studies- International Periodical for the Languages, Literature and History of Turkish or Turkic, 9(5), 1747-1760.

Köse, E. (2013). Bilimsel araştırma modelleri. R. Kıncal. (Ed.), Bilimsel araştırma yöntemleri (99-123) (2. Baskı) Ankara: Nobel Yayın Dağıtım.

Lüle Mert, E. (2015). Türkçe öğretmeni adaylarının konuşma kaygılarına ilişkin bir inceleme. Uluslararası Sosyal Araş̧tırmalar Dergisi, 8 (37), 784-789.

Maviş, A. (2013). Etkili ve başarll konuşma sanatı. İstanbul: Yediveren Yayınları.

MEB (2008). Türkçe öğretmeni özel alan yeterlikleri. 20.12.2016 tarihinde http://otmg.meb.gov.tr/belgeler/ogretmen_yeterlikleri_kitabi/\%C3\%96\%C4 \%9Fretmen Yeterlikleri_Kitab\%C4\%B1_t\%C3\%BCrk\%C3\%A7e \%C3\%B 6\%C4\%9Fretmeni_\%C3\%B6zel alan yeterlikleri_ilk\%C3\%B6\%C4\%9Freti m_par\%C3\%A7a_4.pdf adresinden alınmıştır.

MEB. (2006). İlköğretim Türkçe dersi (6, 7, 8. sinfflar) öğretim programı. Ankara: MEB.

Neer, M. R. ve Kircher, W. F. (1989). The effects of delivery skills instruction on speech anxiety. Paper presented at the Annual Meeting of the Central States Communication Association, Kansas City, MO, April 13-16.

Özkan, E. ve Kınay, İ. (2015). Öğretmen adaylarının konuşma kaygılarının incelenmesi (Ziya Gökalp Eğitim Fakültesi örneği). Uluslararası Türkçe Edebiyat Kültür Eğitim Dergisi, 4 (3), 1290-1301.

Rector, N. A., Bourdeau, D., Kitchen, K. \& Joseph-Massiah, L. (2008). Anxiety disorders: an information guide. Canada: Centre for Addiction and Mental Health.

Sevim, O. (2012). Öğretmen adaylarına yönelik konuşma kaygısı ölçeği: bir geçerlik ve güvenirlik çalışması. Turkish Studies International Periodical For the Languages, Literature and History of Turkish or Turkic, 7 (2), 927-937.

Sevim, O. (2014). Effects of drama method on speaking anxieties of preservice teachers and their opinions about the method. Educational Research and Reviews, 9(18), 734-742.

Taşer, S. (1992). Konuşma eğitimi. İzmir: İleri Kitabevi.

Temiz, E. (2015). Pedagojik formasyon alan öğretmen adaylarının konuşma kaygıları. Turkish Studies International Periodical For The Languages, Literature and History of Turkish or Turkic, 10 (3), 985-992.

Temizkan, M. (2009). Akran değerlendirmenin konuşma becerisinin geliştirilmesi üzerindeki etkisi. Mustafa Kemal Üniversitesi Sosyal Bilimler Enstitüsü Dergisi, 6 (12), 90-112.

Vural, B. (2004). Toplum önünde etkili ve başarıll konuşma. İstanbul: Hayat Yayıncılık.

Yalçın, A. (2012). Türkçe öğretim yöntemleri yeni yaklaşımlar. Ankara: Akçağ Yayınları. 


\section{Serpil ÖZDEMIR}

Yau-hau Tse, A. (2011). To be anxious or not to be anxious-that is the question in public speaking. $\quad 04.07 .2017 \quad$ tarihinde http://umpir.ump.edu.my/2283/1/Andrew_Yau-hau_Tse.pdf adresinden alınmıştır. 
Türkçe öğretmeni adaylarının konuşma kaygılarını gidermede hazırlıklı...

\section{EXTENDED ABSTRACT}

\section{Introduction}

Anxiety refers to unpleasant emotional and observable reactions such as sadness and tension in stressful situations (Demirel, 2010, 78). At the normal level anxiety helps the person to be willing, taking decisions, generating energy in accordance with the decisions taken and to improving performance using this energy (Burkovik, 2009, 32-33). It is considered normal to feel anxiety as long as our work, social life and daily responsibilities are not adversely affected. Even low and moderate anxiety can positively affect performance (Rector et all, 2008, 5-6). High level of anxiety leads to disorder the cognitive, physical and behavioral responses. Cognitive problems such as forgetting what they say; physical problems such as excessive sweating, tremor of voice, trembling of hands; behavioral problems such as not cathing the eye of the listener, making exaggerated movements indicating that they are uncomfortable, not showing a safe posture, shortcuts in speech, excessive speed speech, making speech gaps are seen in people with high anxiety about speaking. Those who have experienced these problems do not transfer their feelings, thoughts and knowledge effectively.

Teaching is one of speaking based professions. The correct and effective speaking of each teacher is an expected situation in terms of being an example to their students. In particular, Turkish teachers should be a model for correct and effective use of Turkish and communication (MEB, 2008, 48). Because Turkish teachers are responsible for educating students who can use voice and body language effectively (MEB, 2006). In general, the speaking concerns of each teacher, especially Turkish teachers and teacher candidates, should be at an acceptable level.

Speaking anxiety is often seen in prepared conversations. The reasons for this can be listed as "lack of information, worry about negative reactions from the listeners, having a shy temperament, diction problems and lack of self-confidence" (Arslan, 2012, 226). It is necessary to be knowledgeable, to be aware of the causes of anxiety, to make good preparations and to practice a lot to be able to overcome anxiety and become a safe speaker. Research shows that prospective Turkish teachers' speaking anxiety decreases after making speaking applications (Bulut, 2015; Sevim, 2014; Katrancı and Kuşdemir, 2015).

The problem of the study was determined as "What the effect is of prepared speaking for prospective teachers' speaking anxiety?" The research has been dealt with in the following sub-problems:

1. What are the prospective Turkish teachers' speaking anxiety levels before and after the prepared speeches?

2. Do the speaking anxiety scores of prospective Turkish teachers show a meaningful difference before and after prepared speeches?

\section{Method}

The study was conducted with a single group pre-test post-test model. The research was conducted with third-year students studying in the Department of Turkish Language Teaching at a faculty of Education of a university at the Western Black Sea Region. The data of the study were collected via "The Speaking Anxiety Scale for Teacher Candidates" developed by Sevim (2012). Forty-one students who attend Speaking Education course 


\section{Serpil ÖZDEMIR}

participated in the research. Research data were analyzed by descriptive statistics and paired sample t-test.

\section{Findings, Discussion and Results}

The study group's speaking anxiety pre-test scores ranged from 2.10 to 3.34 . These scores indicate that the teacher candidates' speaking concerns are moderate. High level speaking anxiety is not seen. The items which have the lowest mean express individual relationship situations. The highest anxiety $\left(\mathrm{X}^{-}=3.34\right)$ has been identified as the item "The idea of speech events such as symposium, panel, conference etc. makes me nerves".

In the post-test, it is seen that the average of all the items decreased. 1-2.3 points show low anxiety and 2.4-3.7 medium level anxiety. The post-test scores are in the low range.

It has been determined that the teacher candidates' speaking anxiety have a significant reduction after prepared speaking. The average level of speaking anxiety scores $(\bar{X}=51.02)$ before the application is moderate. After the prepared speaking applications, the speaking anxiety decreased to $\bar{X}=42.9$. This score shows a low level of anxiety. As a result, it can be said that the prepared speaking applications have an important effect in reducing the teacher candidates' speaking anxiety.

It was determined in this research that speaking in public creates a higher level of anxiety than unprepared speech. Akkaya (2012) also found that excitement in front of the community was the most expressed speaking problem by teacher candidates. This situation has cognitive and affective reasons. Arslan (2012) found that university students are reluctant to speak to the community for reasons such as "encountering sarcastic behaviour, lack of self-confidence, fear of giving false or incomplete information, shy temperament, not being accustomed to talking to the community, worry about not understanding".

It was seen that the post-test scores fell slightly in all items, and this decline was found to be at the low level. This result is parallel with the research conducted by Özkan ve Kinay (2015), Temiz (2015) and Baki and Karakuş (2015) and Lüle Mert (2015). As low and moderate anxiety support better performance (Burkovik, 2009), the anxiety levels of teacher candidates can be regarded as normal.

It was determined that the difference between the pre and post-tests averages was significant. Experimental studies show similar results (Bulut, 2015; Katrancı and Kuşdemir, 2015; Sevim, 2014). As a result, it can be said that the practice of prepared speech has an important effect on reducing the teacher candidates' speaking anxiety.

The practices of this research were based on the activities in National Ministry of Education Turkish Curriculum. "Ours, animation (Hacivat and Karagöz), I wish I were a minister, meddah is in the classroom, I am a guide, cross-query, dialogue" are based on getting into the role of someone else, and "monkey opened its eyes, my dreams and a beautiful day" are the activities based on the individual's own experience. Experimental studies can be done to determine whether role-playing or individual speaking is more effective on the eliminating speaking anxiety.

Based on the findings of this research; It is suggested that oral expression practices should not be neglected in speaking education courses, teacher candidates should be informed about strategies to cope with anxiety and to be supported for having experience in speech environments such as symposiums, panels, conferences and so on. 